\title{
Clinical and Epidemiological Characteristics of COVID-19 in Mayan Pregnant Women of Yucatan, Mexico
}

\author{
Rodríguez Angulo $\mathrm{E}^{1 *}$, Domínguez Enríquez $\mathrm{M}^{2}$, Rosado-Alcocer $\mathbf{L}^{1}$, Ortiz Panozo ${ }^{3}$, Oliva \\ Peña $Y^{1}$, Hoil Santos $J^{1}$ and Andueza Pech $G^{1}$ \\ ${ }^{1}$ Autonomous University of Yucatán, Mexico \\ ${ }^{2}$ Hospital General "Dr. Agustín O’Horán"2 Secretaría de Salud de Yucatán, Mexico \\ ${ }^{3}$ Instituto Nacional de Salud Pública de México, Mexico
}

*Corresponding author: Elsa María Rodríguez Angulo, Social-Medicine Laboratory, Center of regional researches "Dr. Hideyo Noguchi", Autonomous University of Yucatán, México.

To Cite This Article: Rodríguez Angulo E, Domínguez Enríquez M, Rosado-Alcocer L, Ortiz Panozo J, Oliva Peña Y, et al., Clinical and Epidemiological Characteristics of COVID-19 in Mayan Pregnant Women of Yucatan, Mexico. Am J Biomed Sci \& Res. 2021 - 12(4). AJBSR.MS.ID.001779. DOI: 10.34297/AJBSR.2021.12.001779.

Received: 門 April 12,2021; Published: 眥 April 26, 2021

\begin{abstract}
Background: The infection with SARS-CoV-2 virus cause coronavirus disease called COVID-19. Pregnant women are a vulnerable group that present a double susceptibility to fall ill due to their condition of pregnancy and the state of immunosuppression to which they are exposed; even more so if women live in places with difficult access to health services.
\end{abstract}

Objective: To describe clinical and epidemiologycal characteristics of COVID-19 in a sample of mayan pregnancy women.

Methods: A cross-sectional, retrospective study was designed and conducted to review clinical records and epidemiological reports of laboratory-confirmed of mayan pregnant women with COVID-19. Scheme of natural history of the disease was used as a model. A group of specialists participated by giving proposals for preventive strategies to primary, secondary and tertiary prevention level. Descriptive statistic was calculated.

Results: The period prevalence of COVID-19 in pregnant women treated at the hospital was 2.8\%. The most frequent ages of the women were in the group of 20-24 years with 14 (37.8\%) cases; and the 15-19 years-old with 9 (24.3\%) cases. The main signs and symptoms that COVID-19 positive pregnant women presented were headache $75.7 \%$, dyspnea $67.6 \%$, fever $62.2 \%$, myalgia 59.5\% and cough $56.8 \%$. Asthma was the principal comorbidity. Only one case needed mechanical ventilation. No deaths occurred.

Conclusions: Must of patients had mild COVID-19 symptoms. More care should be exercised in treatments that have not yet proven their positive effects for the disease and the side effects that pregnant women and their products may present. Promotion of healthy pregnancy with hygiene and social distancing measures to prevent COVID-19 were measurement proposed.

Keywords: Mayan Pregnancy Women, COVID-19

\section{Introduction}

In December 2019, the transmission of a new coronavirus called SARS-CoV-2 began in Wuhan, China and caused the COVID-19 disease; spreading rapidly to the world and producing the pandemic that is active until now [1]. As of March 2021, 120 million cases of COVID-19 have been registered in the world, of which 2 million resulted fatal [2]. The sudden outbreak and spread of COVID-19 led to a serious challenge to the global public health system. It has been observed that the SARS-CoV-2 coronavirus can induce clinical manifestations similar to those presented by the coronavirus that causes Severe Acute Respiratory Syndrome (SARS) and Middle East Respiratory Syndrome (MERS) [3]. SARS-CoV-2 causes clinical symptoms that can migrate from mild respiratory symptoms to 
severe respiratory failure, requiring intensive care and can lead to asphyxia and death. In some cases, the infection is asymptomatic, generating a dangerous potential state of contagion [4]. As the COVID-19 outbreak has developed, articles have been published in order to understand and analyze the natural history of the disease, recognize which could be the most susceptible hosts, the genomic sequence to develop treatments and prevention, as well such as clinical characteristics and complications [5]. So far, it is known that the COVID-19 disease can be suffered by anyone in any age group, but older adults are the ones who most recently experience its effects, mainly those who suffer from comorbidities [6]. However, there are vulnerable groups such as pregnant women, in which information on the evolution of the disease is scarce; they present a double susceptibility to fall ill due to their condition of pregnancy and the state of immunosuppression to which they are exposed. Despite this risk, it seems that women in pregnancy have mild to moderate COVID-19 symptoms, but those who have fallen ill in the last trimester had the most serious conditions [7]. In SARS and MERS, up to $35 \%$ and $41 \%$ of pregnant patients required mechanical ventilation, and mortality rates were as high as $18 \%$ and $25 \%$, respectively. Likewise, it has been documented that in previous pandemics due to SARS-CoV1 in 2003 and H1N1 in 2009, pregnant women were more susceptible to serious diseases and had higher mortality rates than the general population [8]. The most common symptoms found in pregnant women with COVID-19 have been fever, cough, myalgia, sore throat and general malaise, some cases with lymphopenia and low transaminase elevations [9]. There is no approved treatment for COVID-19. The World Health Organization (WHO) recommended general guidelines for managing symptoms only and advises being cautious with pediatric patients, pregnant women, and patients with underlying comorbidities. Recommended care is to provide supportive management according to the needs of each patient, such as antipyretics for fever and oxygen therapy for patients with respiratory distress. In addition, the recommendations for severe cases are to administer empirical antimicrobial therapy and implement mechanical ventilation depending on the clinical condition of the patient [10]. In the case of pregnant women, several therapeutic options have been considered, among which remdesivir and hydroxychloroquine stand out. However, the benefits and potential risks to the mother and child must be carefully weighed [11]. Regarding the biochemical studies that can help the prognostic of severity, interleukin-6 and D-dimer are indicators that must be taken into account as prognostic factors [12]. In Mexico, since March 2020, 2,227,842 total cases and 201,826 deaths have been confirmed by COVID-19, with this it has migrated from the phase I of mitigation of the epidemic, to phase II of community transmission and currently it has entered to phase III of expansion of the disease in the population, during which there have been, at two times in 2020, an increase and decrease in cases until reaching a plateau; and currently with the prognostic of a third increase due to the entry into the country of variants of new strains of SARSCoV-2 [13]. In the State of Yucatán, 39,954 accumulated cases have been reported until March 29, 2021, with more than 3,000 deaths [14]. We do not know how many cases have occurred in pregnant women and what their clinical evolution has been, what clinical manifestations they have presented and what strategies can be carried out to prevent COVID-19 or limit the damage caused by the disease in pregnant women in Yucatán. In the Mayan communities of Yucatán, pregnant women who fall ill must go to their closest health center and second-level hospital, which are located on the care route that the local health system has established. In studies carried out in Yucatán, these routes have been studied and barriers causing delays care were observed, even when arriving at the hospital, which are being treated $[15,16]$. Therefore, the purpose of this study is to describe the prevalence of signs and symptoms of COVID-19 in pregnant women from Mayan communities who were treated at the O'Horán hospital and propose strategies aimed at limiting the damage at the three levels of prevention.

\section{Methods}

A cross-sectional, retrospective study was designed and conducted to review clinical records and epidemiological reports of laboratory-confirmed pregnant women with COVID-19. In order to have access to the data from the files and epidemiological studies, authorization was requested from the Hospital Ethics Committee, who reviewed the protocol and gave authorization to carry out the study. From April 2020 to January 2021, clinical data of pregnant women admitted to the General Hospital "Dr. Agustín O’Horán " belonging to the Ministry of Health of the State of Yucatán (SSY), Mexico, were reviewed. Based on the diagnosis on the definition of a suspected, probable and positive case of COVID-19 [17], the pregnant women were referred from health centers in various locations in the State to the hospital, due to fever, cough, fatigue and respiratory distress. In the hospital, each pregnant woman underwent a real-time polymerase chain reaction test (RT-PCR) on nasopharyngeal swab, which demonstrated the presence of SARS-CoV-2 virus nucleic acid. The data collected from the files and epidemiological studies were age, municipality of origin, months of gestation, signs and symptoms, comorbidities, days elapsed between the onset of symptoms and admission, days of stay, duration of the clinical manifestations and history of exposure to contact with suspicious or positive respiratory symptoms for COVID-19 two weeks before the onset of symptoms [18]; lymphocyte and D-dimer levels were analyzed. The information collected on the clinical symptoms of COVID-19 in pregnant women was represented using the Leavell \& Clarck [19] scheme of natural history of the disease (HNE) as a model. Finally, specialists in the care of pregnant women were asked to review the HNE scheme for COVID-19, who proposed preventive strategies for each level of prevention. The information was delivered to the decision makers of the localities where the women came from. 


\section{Participating Specialists}

The specialists who participated by giving proposals for preventive strategies were four women and two men: an obstetrician, a specialist in social anthropology, two doctors in education, and two epidemiologists. The obstetrician and epidemiologists worked in clinical areas of care for pregnant women with more than 5 years of experience; and the other specialists had accumulated experience and knowledge in research of more than 20 years, in medico-social studies on sociocultural characteristics, routes and barriers to care for pregnant women in the State of Yucatán. Based on their experience and specialty, each specialist analyzed the HNE scheme and proposed preventive strategies for the selected level of prevention. Each specialist made a written list of the strategies, which were distributed in the HNE scheme as appropriate.

\section{Statistic Analysis}

The data collected from clinical records and epidemiological studies were captured in a database and subsequently analyzed with the support of the EPI-Info Vs. 7.0 program. For continuous variables, means and standard deviation were calculated; and for the qualitative percentages. The prevalence of COVID-19 was calculated in pregnant women treated in the hospital during the study period.

\section{Results}

\section{Epidemiological Characteristics}

From April 2020 to January 2021, clinical and epidemiological data were collected from 37 pregnant women diagnosed with COVID-19 at the General Hospital “Dr. Agustín O’Horán ” of the SSY. The period prevalence of COVID-19 in pregnant women treated at the hospital was $2.8 \%$. Of the total positive cases, $33(89.2 \%)$ required hospitalization and $4(10.8 \%)$ were ambulatory. The first positive case was confirmed on April 23, 2020, and the last was diagnosed on January 15, 2021. 13 (35.1\%) women reported having had contact with a suspected COVID-19 case two weeks before falling ill. The most frequent ages of the women were in the group of 20-24 years with 14 (37.8\%) cases; and the $15-19$ yearsold with $9(24.3 \%)$ cases (Table 1). $87 \%$ of the pregnant women had completed secondary school, 58\% lived in common union and $94.6 \%$ were dedicated to housework. The cases came from $16 / 32$ municipalities of the State and $59.5 \%$ of them were women referred from localities whose journey took between thirty and ninety minutes to reach the O’Horán hospital (Figure 1).

Table 1: Age of pregnant women with COVID-19 attended in the General Hospital “Dr. Agustin O’Horán” of Yucatan, Mexico.

\begin{tabular}{|c|c|c|}
\hline Age & n & \% \\
\hline $15-19$ & 9 & 24.3 \\
\hline $20-24$ & 14 & 37.8 \\
\hline $25-29$ & 5 & 13.5 \\
\hline $30-34$ & 3 & 8.2 \\
\hline $35-39$ & 4 & 10.8 \\
\hline $40-44$ & 2 & 5.4 \\
\hline TOTAL & 37 & 100 \\
\hline
\end{tabular}

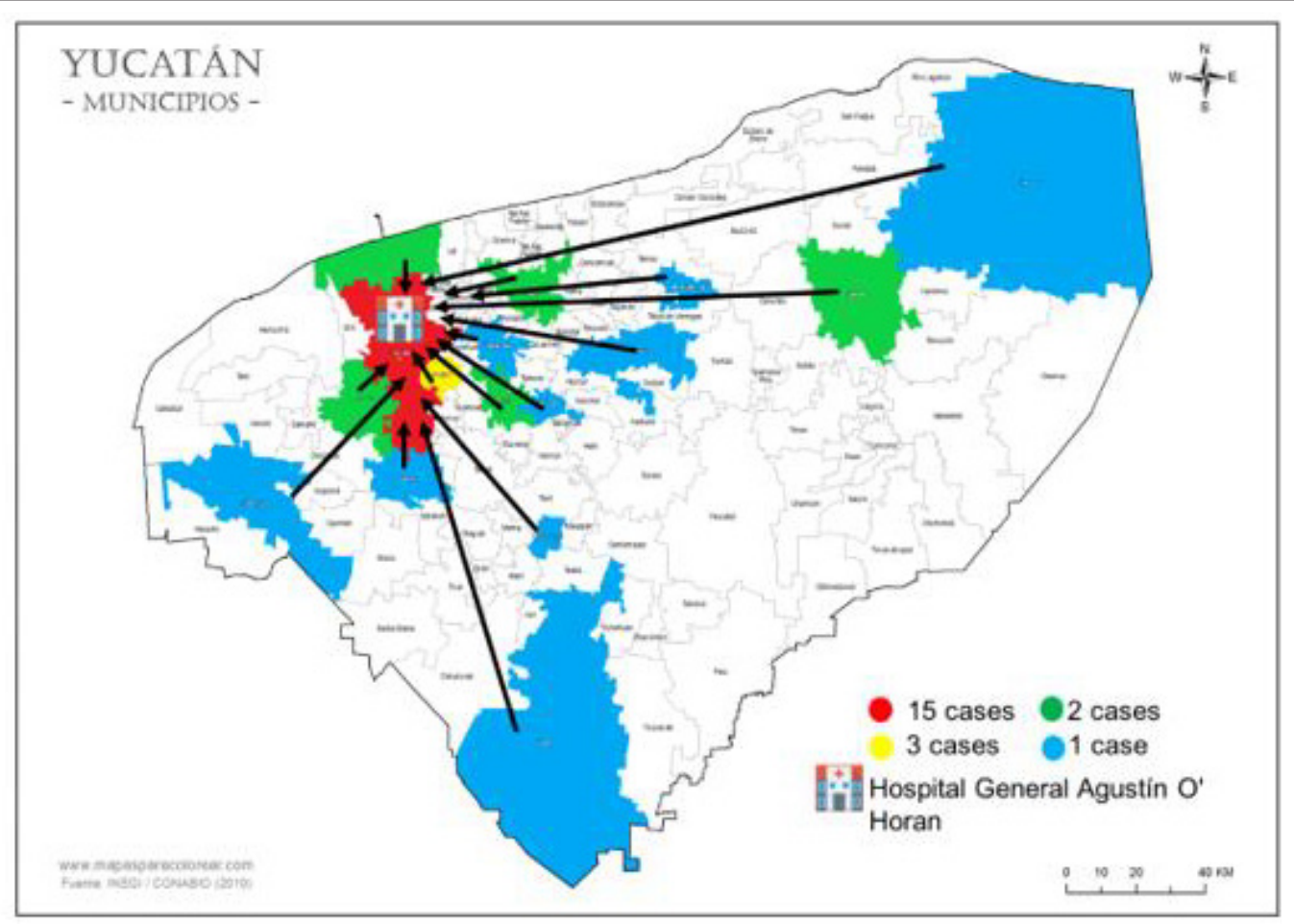

Figure 1: Municipalities with cases of mayan pregnant women with COVID-19 referred to Hospital O'Horán. Yucatán, Mexico. 


\section{Clinical Features}

Of the 37 positive cases of pregnant women with COVID-19 studied, $30(81.1 \%)$ were in the third trimester of pregnancy and most primiparous 20 (56.7\%). 35 (97\%) of the cases had prenatal control with at least five prenatal consultations. 24 (64.8\%) sought help between the first and fourth day from the onset of symptoms (Table 2) In 14 (37.8\%) women, the onset of the condition was sudden. The main signs and symptoms that COVID-19 positive pregnant women presented were headache $75.7 \%$, dyspnea $67.6 \%$, fever $62.2 \%$, myalgia $59.5 \%$ and cough $56.8 \%$ (Table 3 ). Other less frequent signs and symptoms were attack of the general state and chills in $32.4 \%$ and $21.6 \%$, respectively. Comorbidities were present in $13(35.1 \%)$ cases, the main ones being asthma in $5(39.0 \%)$ and arterial hypertension in 3 (23.0\%) (Figure 2); in 2 (15.4\%) cases there was more than one comorbidity. The average number of days elapsed between the onset of symptoms and admission to the hospital was $2.8 \pm 2.4$ days. The average days of hospital stay was $5.2 \pm 3.9$ days. The average number of days that the entire illness lasted was $10.8 \pm 8.8$ days. Regarding the treatment of the cases, 10 $(27.0 \%)$ received antimicrobial treatment, 9 (24.3\%) anticoagulant, $3(8.1 \%)$ corticosteroid and 1 (2.7\%) hydroxychloroquine. $17 \%$ of the cases required supportive oxygen and 1 (2.7\%) required mechanical ventilation. 23 (63\%) had lymphopenia and 36 (97\%) with a D-dimer greater than 1 . No deaths occurred in the women studied.
Table 2: Time elapsed between the first symptom and reach for care.

\begin{tabular}{|c|c|c|}
\hline Time & $\mathbf{n}$ & $\mathbf{\%}$ \\
\hline$<24$ horas & 7 & 19 \\
\hline 1 - 4 días & 24 & 64.8 \\
\hline 5 - 10 días & 6 & 16.2 \\
\hline TOTAL & 37 & 100 \\
\hline
\end{tabular}

Table 3: Signs and symptoms of COVID-19 showed for pregnant women.

\begin{tabular}{|c|c|c|}
\hline Signs and symptoms & Yes \% (n) & Not \% (n) \\
\hline Headache & $75.7 \%(28)$ & $24.3 \%(9)$ \\
\hline Dyspnoea & $67.6 \%(12)$ & $32.4 \%(25)$ \\
\hline Fever & $62.2 \%(23)$ & $37.8 \%(14)$ \\
\hline Myalgia & $59.5 \%(15)$ & $40.5 \%(22)$ \\
\hline Cough & $56.8 \%(21)$ & $43.2 \%(16)$ \\
\hline Sore throat & $35.1 \%(13)$ & $64.9 \%(24)$ \\
\hline Arthralgia & $35.1 \%(13)$ & $64.9 \%(24)$ \\
\hline Rhinorrhea & $32.4 \%(12)$ & $67.6 \%(25)$ \\
\hline Loss of taste & $18.9 \%(7)$ & $81.1 \%(30)$ \\
\hline Loss of smell & $16.2 \%(6)$ & $83.8 \%(31)$ \\
\hline Chest pain & $16.2 \%(6)$ & $83.8 \%(31)$ \\
\hline Diarrhoea & $13.5 \%(5)$ & $86.5 \%(32)$ \\
\hline
\end{tabular}

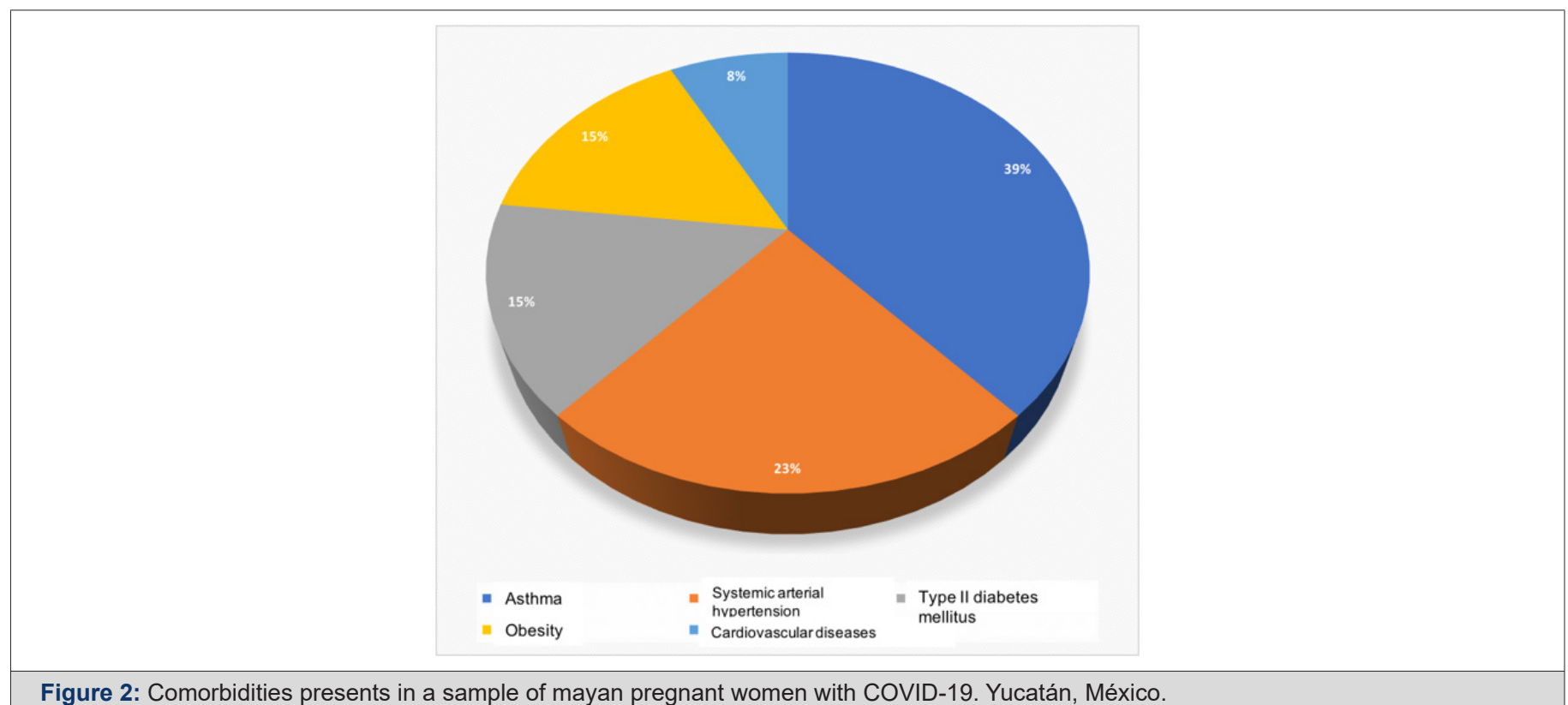

\section{Preventive Strategies}

The specialists proposed strategies for primary, secondary and tertiary levels of prevention. For primary prevention they were related to healthy lifestyles, prevention of risk factors and comorbidities; and specific actions for a healthy pregnancy with hygiene and social distancing measures to prevent COVID-19.
For secondary prevention, the case definitions for COVID-19 and specific tests for the diagnosis of the SARS-CoV-2 virus and prognostic factors of the disease for timely detection; and home treatment based on anti-inflammatories and hydration. For tertiary prevention, oxygen support and mechanical ventilation, as well as limiting damage from sequelae and disabilities (Figure 3). 


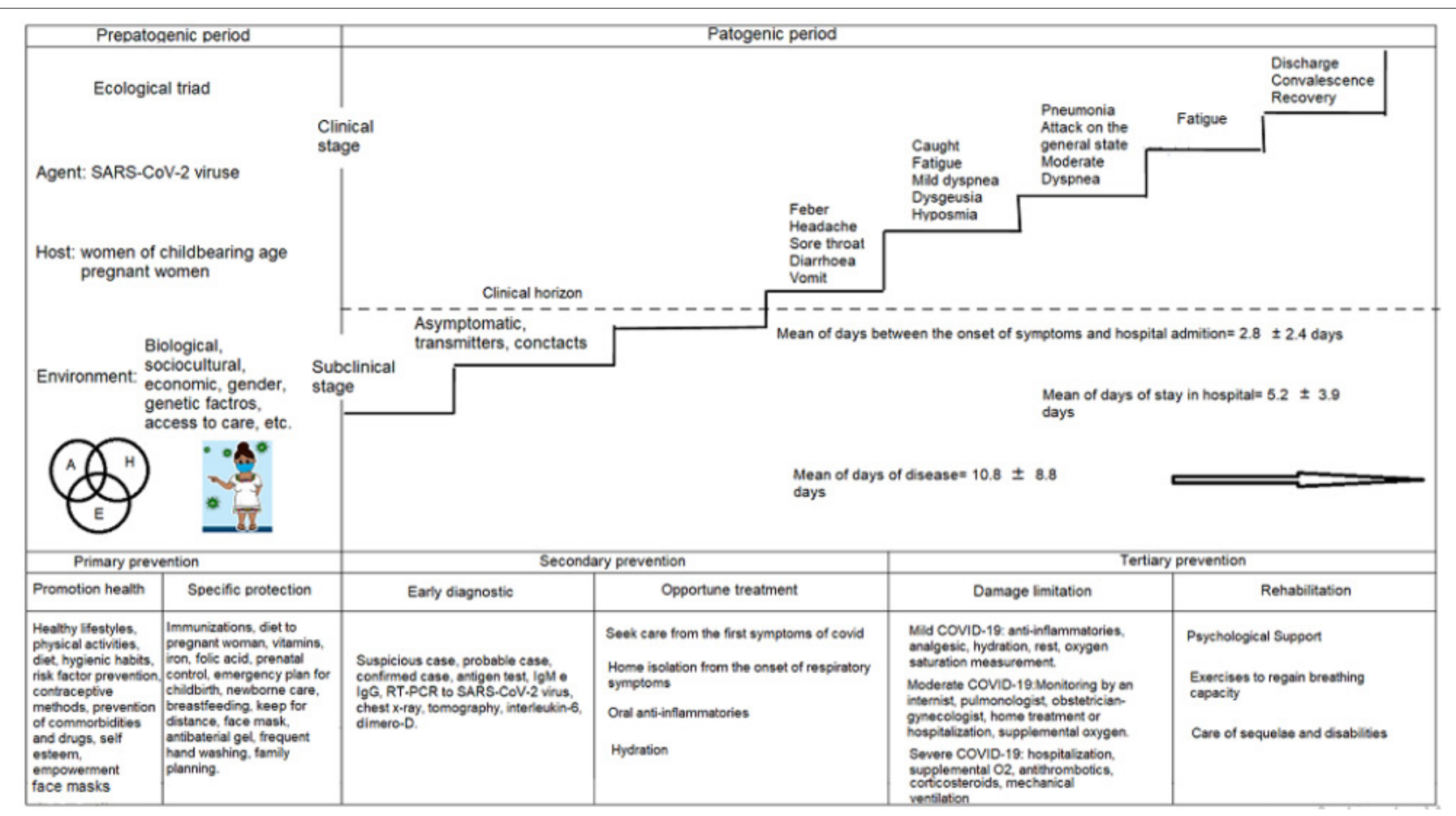

Figure 3: Disease natural history of COVID-19 in a sample of Mayan pregnant women of Yucatan, Mexico.

\section{Discussion}

The physiological changes inherent in pregnancy make women with this condition more susceptible to presenting a severe SARSCoV2 infection, which occurs more frequently in the third trimester [7]. In this study, we observed that the population of pregnant women with the highestadmission due to SARS-CoV2 infection were patients who were in the third trimester. It has been reported that patients who have had severe clinical manifestations of COVID-19 presented some comorbidity such as diabetes, hypertension, bronchial asthma and smoking [20]. In this study, asthma was observed more frequently as a comorbidity, however, arterial hypertension was also present, which is consistent with the reports of pregnant women who have become ill in other countries [6]. The age group with the highest number of positive COVID-19 cases in Mexican statistics correspond to women between 20-39 years [21]. However, in the present study we found that the population of pregnant women at an earlier age is becoming ill from COVID-19 (15 to 29 years old).

Despite having reports of the highest number of deaths in patients who were in the third trimester of pregnancy (20), at the Hospital “Dr. Agustin O'Horán during the study period no maternal death secondary to SARS-CoV-2 infection was reported. Likewise, all the gestation products were obtained alive and in good general condition, although it was not possible to determine whether they had some degree of respiratory distress at birth since the reviewed clinical records did not mention Silverman's score.
The clinical presentation of cases of SARS-CoV2 infection is very broad, most cases develop mild symptoms, around 40\% develop pneumonia, and 5\% develop respiratory failure [22]. In this study it was found that most of the patients had mild COVID-19 symptoms, which were characterized mainly by headache, dyspnoea, fever, myalgia and cough, $8 \%$ had pneumonia and $17 \%$ required the use of supplemental oxygen, so only $2.7 \%$ required the use of mechanical ventilation, the latter was a lower percentage than that reported in the literature [23].

The type of medical treatment in hospitalized patients was varied, mainly based on symptomatic management and antithrombotic prophylaxis; the use of corticosteroids was used in patients with pneumonia and some other underlying lung disease, such as asthma. However, the use of antibiotics and hydroxychloroquine in some cases could not be justified, because its use was not clarified in the clinical record. More care should be exercised in this regard, especially in the reasons why treatments are used that have not yet proven their positive effects for the disease and the side effects that pregnant women and their products may present. As is the case with hydroxychloroquine, which although the FDA authorized its emergency use due to the pandemic, its high toxicity could lead to severe undesirable effects on the pregnant woman and her future child [24].

Cochrane reviews have found that D-dimer levels greater than $1.0 \mathrm{mg} / \mathrm{L}$ at admission are associated with a worse prognosis for COVID-19. In our study, of patients admitted with a positive PCR 
result, $97 \%$ of them had D-dimer levels greater than $1.0 \mathrm{mg} / \mathrm{L}$; but only one patient required mechanical ventilation despite having reported a D-dimer on admission of $1.53 \mathrm{mg} / \mathrm{L}$. Regarding the rest of the biochemical parameters, lymphopenia has been associated with SARS-Cov2 infections [25], in the review of this study we found that $63 \%$ of the patients had lymphopenia, which corresponds to the bibliography. The knowledge of these alterations added to the clinical of the patient and the risk factors could be useful at the time of the diagnosis and prognosis of the patient, to decide a therapeutic plan until having the definitive result, which until now, the most Specific is the PCR test, which has the disadvantage of taking 24-72 h. in obtaining the result.

\section{Conflict of Interest}

\section{None}

\section{Acknowledgments}

The authors give thanks to Consejo Nacional de Ciencia y Tecnología (CONACYT-México) for the funds destined to carry out this study.

\section{References}

1. Sonja A Rasmussen J, Smulian J Lednicky T, Wen D Jamieson, et al (2020) Coronavirus Disease 2019 (COVID-19) and pregnancy: what obstetricians need to know. Am J Obstet Gynecol 222(5): 415-426.

2. (2021) World Health Organization (WHO). Coronavirus Disease (COVID-19) Outbreak.

3. Xiao Wei Xu, Xiao Xin Wu, Xian Gao Jiang, Kai Jin Xu, Ling Jun Ying, et al. (2020) Clinical findings in a group of patients infected with the 2019 novel coronavirus (SARS-Cov-2) outside of Wuhan, China: retrospective case series. BMJ 368: 606.

4. Dawei Lu, Lin Sang, Shihua Du, Tao Li, Yange Chang, et al. (2020) Asymptomatic COVID-19 infection in late pregnancy indicated no vertical transmission. J Med Virol 92(9): 1660-1664.

5. Kably Ambe A, Olavarría Guadarrama MY, Sánchez Aranda A, Roque Sánchez AM, Alonso de Mendieta M, et al. (2020) COVID-19 y sus repercusiones en la práctica ginecoobstétrica. Ginecol Obstet Mex 88: $1-12$.

6. Yiyin Chen, Sabra L Klein, Brian T Garibaldi, Huifen Li, Cunjin Wu, et al (2021) Aging in COVID-19: Vulnerability, immunity and intervention. Ageing Res Rev 65: 101205.

7. Dashraath P, Jing Lin Jeslyn W, Mei Xian Karen L, Mahesh Choolani, Citra Mattar, et al. (2020) Coronavirus Disease 2019 (COVID-19) Pandemic and Pregnancy. Am J Obstet Gynecol 222(6): 521-531.

8. Breslin N, Baptiste C, Gyamfi-Bannerman C, Miller R, Martinez R, et al. (2020) COVID-19 infection among asymptomatic and symptomatic pregnant women: Two weeks of confirmed presentations to an affiliated pair of New York City hospitals. American Journal of Obstetrics \& Gynecology.

9. Mullins E, Evans D, Viner R, O’Brien P, Morris E (2020) Coronavirus in pregnancy and delivery: rapid review. Ultrasound Obstet Gynecol 55(5): 586-592.

10. Tobaiqy M, Qashqary M, Al-Dahery S, Mujallad A, Hershan A, et al. (2020) Therapeutic Management of COVID-19 Patients: A systematic review Infection Prevention in Practice 2(3): 100061.

11. Stumpfe FM, Titzmann A, Schneider MO, Stelzl P, Kehl S, et al. (2020) SARS-CoV-2 Infection in Pregnancy - a Review of the Current Literature and Possible Impact on Maternal and Neonatal Outcome [SARS-CoV2-Infektion in der Schwangerschaft - eine Übersichtsarbeit über die aktuelle Literatur und mögliche Einflüsse auf das maternale und neonatale Outcome]. Geburtshilfe Frauenheilkd. 80(4): 380-390.

12. Yong Gao, Tuantuan Li, Mingfeng Han, Xiuyong Li, Dong Wu, et al. (2020) Diagnostic utility of clinical laboratory data determinations for patients with the severe COVID-19. J Med Virol 92(7): 791-796.

13. Taboada B, Vazquez-Perez J, Muñoz-Medina J, Ramos-Cervantes P, Escalera-Zamudio M, et al. (2020) Genomic Analysis of Early SARS-CoV-2 Variants Introduced in Mexico. J Virol 94(18): e01056-20.

14. Gobierno de México. Dirección General de Epidemiología. Subsecretaría de prevención y promoción de la salud.

15. Rodríguez Angulo E, Oliva Peña Y, Ojeda Rodríguez R, Andueza Pech M (2020) Prolonged Response Times in Obstetric Emergency Care Out of Hospital in Yucatan, Mexico. Open Access Journal of Biomedical Science 2(1): 292-300.

16. Rodríguez Angulo E, Uc Santos G, Gómez Carro S. Maternal hospital deaths: clinical and sociodemographic characteristics in Yucatán, México. Obstetrics \& Gynecology International Journal. 2020; 11(6): 374-379 DOI:10.15406/ogij.2020.11.00539

17. Gobierno de México (2020). Lineamiento estandarizado para la vigilancia epidemiológica y por laboratorio de la enfermedad respiratoria viral. Secretaría de Salud. Subsecretaría de prevención y promoción de la salud. Dirección General de Epidemiología. pp 1-74

18. Tong ZD, Tang A, Li KF, Li P, Wang HL, et al. (2020) Potential Presymptomatic Transmission of SARS-CoV-2, Zhejiang Province, China, 2020. Emerg Infect Dis 26(5): 1052-1054.

19. Leavell HR, Clark EG (1965) Preventive Medicine for the Doctor in His Community. New York: McGraw-Hill Book Company.

20. Organización Panamericana de la Salud / Organización Mundial de la Salud. Alerta Epidemiológica: COVID-19 en el embarazo, 13 de agosto de 2020, Washington,USA.

21. Lira-Lucio JA, Roldán-Rodríguez E, Ochoa-Millán JG, Hernández-Escobar L, Padilla-Rivera CI, et al. (2020) Factores asociados a mal pronóstico en embarazadas con diagnóstico de SARS-CoV-2. Ginecol Obstet Mex 88(7): 450-457.

22. Organización Panamericana de la Salud / Organización Mundial de la Salud. Alerta Epidemiológica: COVID-19, complicaciones y secuelas. 12 de agosto de 2020, Washington, USA.

23. Lucarelli E, Behn C, Lashley S, Smok D, Benito C, et al. (2020) Mechanical Ventilation in Pregnancy Due to COVID-19: A Cohort of Three Cases. Am J Perinatol 37(10): 1066-1069.

24. Chary M, Barbuto A, Izadmehr S, Hayes B, Burns M (2020) COVID-19: Therapeutics and Their Toxicities. J Med Toxicol 16(3): 284-294.

25. López M, Gonce A, Meler E, Plaza A, Hernández S, et al. (2020) Coronavirus Disease 2019 in Pregnancy: A Clinical Management Protocol 